\title{
DE LA ISLA A LA FRONTERA. LA PROBLEMATIZACIÓN DEL ESPACIO EN LA FICCIÓN DISTÓPICA CONTEMPORÁNEA
}

\author{
Marc VILLANUEVA MIR \\ Universitat de Barcelona \\ marcvillanuevaimir@gmail.com
}

\begin{abstract}
La littérature est indissolublement une science de la société et la création d'une mythologie nouvelle. À partir de là se définit l'identité d'une poétique et d'une politique.
\end{abstract}

Jacques Rancière (2007: 19)

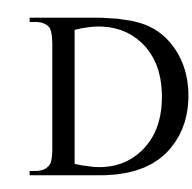
urante la primera mitad del siglo XX, la aparición de novelas como Brave New World (Huxley, 1932) o Nineteen Eighty-Four (Orwell, 1949) fue rápidamente celebrada por la crítica como el nacimiento de un nuevo género literario, marcado por la tumultuosa realidad política y social de la época y por un fuerte sentimiento de inseguridad y desconfianza hacia el futuro inmediato. Aunque las guerras mundiales jugaron aquí un papel clave, es ante todo el fracaso de los grandes proyectos utópicos del siglo XX (en especial el socialismo, pero también la fe en el potencial emancipador de la ciencia y la tecnología) lo que acabó contribuyendo de modo decisivo a la construcción de dicho pesimismo. El éxito alcanzado por las primeras distopías permitió fijar rápidamente una serie de rasgos que se considerarían característicos del nuevo género distópico: la distopía aparecería como expresión literaria de la desconfianza para con la utopía, a través de una ficción prospectiva que presentaría un mundo abominable instalado en un futuro cercano, y donde se plantearían problemas relacionados con la deshumanización, la alienación o la manipulación de la verdad, a menudo en escenarios posapocalípticos, ya sean desolados o bien superpoblados, sometidos a un rígido control o inmersos en una anomia radical (di Minico, 2015: 6-7).

Si bien este conjunto de características puede observarse en el grueso de novelas distópicas escritas durante la primera mitad del siglo XX bajo el influjo directo de Huxley y Orwell $-\mathrm{y}$ a las que, siguiendo a Domingo (2008), llamaremos «distopías clásicas»-, estos rasgos, demasiado anclados en la descripción de un modelo originario, se revelan insuficientes para analizar algunas de las transformaciones que el género distópico ha experimentado en las últimas décadas. De ello resulta una imagen anquilosada de la distopía, al mismo tiempo que se pierde la oportunidad de observar el fenómeno distópico en su conjunto; un fenómeno que va más allá de la literatura, desbordando los 
límites de la novela como medio (por lo que juzgamos conveniente hablar, de ahora en adelante, de «ficción distópica») e incidiendo y desarrollándose en una gran cantidad de manifestaciones culturales, a menudo vinculadas a un consumo de masas. Este es el caso de películas, cómics, videojuegos o ficciones audiovisuales seriadas, como Blade Runner, V for Vendetta, Black Mirror o Westworld.

Para hallar un sentido crítico en tal proliferación de muestras, que nos permita a la vez detectar las innovaciones formales del género y ponerlas en relación con la representación que, a través suyo, se hace del mundo - lo que, en palabras de Pavel (2003: 41) constituye el acierto de toda obra narrativa-, no basta con abordar dichas ficciones únicamente desde una lógica genérica de tipo genealógico (Schaeffer, 1989), sino que esta debe completarse con una aproximación de tipo analógico, que nos permita leer determinados textos desde la óptica de la distopía, aun cuando los componentes más característicos del género se encuentren ausentes en ellos. Esta operación nos permitirá destacar, en un discurso transmedial, el eje desde el que queremos observar la ficción distópica contemporánea, el cual, ya lo adelantamos, tiene que ver con el diálogo que esta sostiene con el pensamiento utópico, a través de una problematización del espacio.

El término «utopía» fue acuñado en 1516 por Thomas More en su obra más célebre ${ }^{1}$, como denominación de una isla imaginaria, sede del estado ideal concebido por el autor. Desde la formación morfológica del concepto, que se plantea como un juego entre ov̉- (prefijo de negación) y દũ̃- (bueno) añadidos a utopía queda ligado a una paradójica dualidad que define simultáneamente el «buen lugar» como «no lugar», al que sólo se puede llegar mediante un «ejercicio explorativo de especulación» (Claeys, 2011: 69). La visita literaria a estos «países inexistentes» (Trousson, 1979) queda, sin embargo, muy lejos de plantearse como una evasión de la realidad. Si la utopía representa «un sueño de perfección social» (López Keller, 1991: 8), la lógica del género utópico consiste en la contraposición de dicha perfección con la imperfección de la sociedad a la que se dirige la obra. Mediante este ejercicio, la literatura utópica trata de hacer visibles las tendencias destructivas del sistema actual, desde la confianza de que la crítica puede, si no abolirlas, sí paliarlas. En este sentido, el fin último de la literatura utópica no es la creación de un mundo fuera del mundo, sino la exploración, a través de un ejercicio dialéctico, del espacio existente «entre lo posible y lo imposible» (Claeys, 2011: 15).

El término «distopía», que sustituye $\varepsilon \tilde{v}^{-}$por $\delta v \varsigma_{-}{ }^{2}$, dispone de un origen muy posterior. Sus primeras manifestaciones no tienen lugar hasta el siglo XVIII (Budakov, 2010), y se repiten de modo esporádico, en forma de juegos de palabras y neologismos, hasta su aparición más conocida, fechada el 12 de marzo de 1868 en sesión parlamentaria de la Cámara de los Comunes, en boca de John Stuart Mill. El intervalo de más de tres siglos que separa ambos términos es significativo. Así como el sustrato cultural de la utopía es el Renacimiento, caracterizado por una plena confianza en la capacidad emancipadora de la razón y del progreso, el concepto «distopía» empezará a circular, desde finales del siglo XVIII, a la sombra de la Revolución Francesa y la Revolución Industrial, que darían lugar a

\footnotetext{
${ }^{1}$ Originalmente en latín: De optimo republica statu, deque nova insula Utopia.

${ }^{2} \Delta$ vs- significaría anormal, doloroso o desfavorable (Domingo, 2008: 23).
} 
escenarios de pesadilla directamente desprendidos del proyecto de la Ilustración. La literatura se hará rápidamente eco de la inseguridad producida por estos acontecimientos. Del mismo modo que, en una especie de anticipación de la Escuela de la Sospecha (Ricoeur, 1965), la novela gótica poblará el imaginario decimonónico de monstruos y fenómenos sobrenaturales, la narrativa de ciencia ficción dará lugar a las primeras visiones distópicas directamente vinculadas al progreso tecnológico y a la evolución de la ciencia.

Ahora bien, el rasgo diferencial del género distópico - y del mismo concepto de distopía — en relación con la ciencia ficción es la dialéctica que este establece con el concepto de utopía, en un reflejo del carácter propiamente contradictorio del proyecto ilustrado. De un modo afín al desempeñado por Horkheimer y Adorno (1969), la distopía traza una correlación directa, casi causal, entre el pensamiento utópico y la realidad totalitaria e inhumana construida por el ser humano. Las estructuras sociales reales, pues, pasan a cuestionar el ideal, en una operación dialéctica inversa a la que proponía el pensamiento utópico, y en una doble oposición al concepto de utopía: en tanto que «buen lugar», ya que el presente se expresaría en términos de «catástrofe»o «barbarie», y en tanto que «no lugar», puesto que la distopía apunta precisamente a la existencia material de la injusticia y la opresión en la sociedad. Usando los conceptos de la Escuela de Frankfurt, es posible decir que la dialéctica idealista de la utopía es refutada aquí por una dialéctica negativa, que presenta a la distopía como una condición inherente al mismo sueño utópico: en este sentido, las ideas de la distopía como utopía bajo sospecha (Domingo, 2008), como sombra de la utopía (Kumar, 2013) o como su esencia misma (Claeys, 2013: 15) nos conducen a la conclusión de que el término «distopía» no puede entenderse como una mera antítesis del de «utopía» ${ }^{3}$.

La novela distópica alcanza un espacio propio en el campo literario a partir de la tercera década del siglo XX. Si bien es cierto que en 1924 ya había aparecido $M b l$ (en inglés, We) de Yevgeny Zamyatin, es especialmente a partir de la publicación de Brave New World y de Nineteen Eighty-Four que se empieza a emplear el concepto «distopía» para designar un nuevo género literario. En términos generales, la ficción distópica puede definirse como «la construcción literaria de sociedades no deseables que como reverso de las utopías nos presentan el peor de los mundos posibles» (Domingo, 2008: 16). Aunque los factores que pueden gobernar este mundo indeseable son múltiples, la instauración de un gobierno represivo o de un sistema pernicioso constituyen la idea dominante en los primeros textos distópicos (di Minico, 2015: 7), de modo que puede decirse que la distopía clásica «nació como narrativa literaria con vocación de novela de política ficción, donde el objetivo último será desentrañar la naturaleza del poder y los mecanismos de dominación» (Domingo, 2008: 24).

El género distópico puede enmarcare, desde este punto de vista, en lo que Fernando Ángel Moreno (2013) llama «literatura prospectiva». Desde una perspectiva genealógica, podemos observar cómo en su configuración participan componentes de otros dos géneros prospectivos, la ciencia ficción

\footnotetext{
${ }^{3}$ La implicación dialéctica, y por lo tanto, móvil, del término «distopía» explicaría, así, su triunfo sobre otros términos posibles, como el contemporáneo «cacotopía» (Budakov, 2011) o, más actualmente, «utopía negativa»o «anti-utopía» (Domingo, 2008: 23).
} 
y la literatura utópica, aunque el tratamiento que dichos componentes reciben en la ficción distópica, marcada por la experiencia totalitaria del siglo XX, difiere en aspectos fundamentales.

La ciencia ficción comparte con la distopía una actitud crítica con los valores ilustrados de la ciencia y la razón como elementos emancipadores del ser humano, ante la amenaza de un futuro deshumanizado donde lo propiamente humano se haya visto disuelto ya sea en una bestia, ya sea en una máquina. Ahora bien, el componente científico o tecnológico extraordinario (que a menudo acerca la ciencia ficción al relato maravilloso) dominante en la ciencia ficción se convierte en un elemento periférico y, por lo tanto, prescindible, en la novela distópica. El auge de nuevos agentes de transformación y movilización de la sociedad durante el siglo XX, como las ciencias sociales, los medios de comunicación de masas o las ideologías totalitarias se traducirá en una modulación temática del género distópico, mucho más interesado por estos fenómenos que por la evolución tecnológica. Así pues, parte del impacto alcanzado por Nineteen Eighty-Four se explica por la escasa distancia tecnológica que separa el mundo de los lectores del mundo de la ficción (López Keller, 1991: 19-20), mientras que en otros casos, como The Handmaid's Tale (Atwood, 1985), esta diferencia es totalmente obviada.

Otra diferencia del género distópico respecto a la ciencia ficción puede ubicarse en los personajes. En la segunda, es muy habitual que el personaje principal sea un científico o alguien cercano a un proceso científico. En The Island of Doctor Moreau (Wells, 1896) no es tan relevante que el protagonista tenga conocimientos universitarios de biología, sino que una fina pared separe su habitación del laboratorio de Moreau, cuya tarea puede entender rápidamente gracias a su formación. En el caso de la novela distópica, nunca encontraremos una vecindad tan extrema con la fuente del conflicto. Aquí, el personaje principal aparece como un everyman - un héroe problemático, en palabras de Lukács (1920) - : se trata de un ser más bien mediocre que se confunde con las masas y que habita un mundo donde la proximidad con el poder o la verdad ya no es posible, puesto que estos han dejado de ocupar una posición claramente localizada y se han transformado en instancias difusas y diseminadas por toda la sociedad, en una interiorización plena del modelo del panóptico. Lejos de cualquier opción de heroísmo (todavía posible en la ciencia ficción), los personajes atrapados en una distopía sólo pueden aspirar a emprender una revuelta privada para abandonar la alienación en la que la sociedad los sitúa.

John, el salvaje de Brave New World, se presenta, en cambio, como refiguración del «visitante forastero» propio de la literatura utópica. La primera diferencia con este género (genealógicamente formado en relación con el diálogo platónico y la novela de viajes) es que, así como este dispone de un contenido narrativo mínimo, la distopía utiliza la acción para explorar los conflictos de la sociedad representada, al mismo tiempo que los efectos que dicha sociedad produce en la psicología del protagonista. En el género utópico, en cambio, el «visitante» no pasa de ser un alter ego del lector, invitado a la exposición de un modelo de funcionamiento social. Es desde este punto de vista que podemos entender la operación de Huxley al «introducir» un personaje moderno como John en un mundo que se presenta a sí mismo a través de los códigos literarios de la utopía. Encontrándolo 
claramente distópico, John reacciona de acuerdo con sus propios códigos, tratando de iniciar una rebelión, y provocando el desconcierto del resto de personajes, que ni siquiera son capaces de reaccionar ante el conflicto.

Una segunda diferencia puede ubicarse en la desaparición del eje temático del viaje. Si, en la novela utópica, el viaje permitía separar con una línea divisoria clara el mundo real del que formaba parte el personaje del mundo ideal al que accedía, en la distopía nos encontramos con una imposibilidad de retorno o de huida de la sociedad en la que este se halla inmerso. Así pues, el viaje utópico hacia el conocimiento reaparece en las distopías en forma de vagabundeo por la propia ciudad, convertida en un laberinto, como en Nineteen Eighty-Four, o en una fortaleza, como en The Handmaid's Tale.

A copia de reformulaciones, el género distópico también ha dado con un modelo de desenlace característico y hasta previsible. Dicho desenlace suele escenificar una conversación persuasiva con el representante de la autoridad, tras la cual el personaje principal acaba por sucumbir al sistema alienante. El doble final de Brave New World representa a la vez el último acto posible de rebelión romántica (con el suicidio de John) y la primera solución de compromiso con el sistema (con el exilio de Bernard). Este segundo gesto de sumisión será el propio de la distopía, como vemos en Nineteen Eighty-Four, donde la traición final de Winston Smith se describe en los términos siguientes:

Contempló el enorme rostro. Le había costado cuarenta años saber qué clase de sonrisa era aquella oculta bajo el bigote negro. ¡Qué cruel e inútil incomprensión! ¡Qué tozudez la suya exiliándose a sí mismo de aquel corazón amante! Dos lágrimas, perfumadas de ginebra, le resbalaron por las mejillas. Pero ya todo estaba arreglado, todo alcanzaba la perfección, la lucha había terminado. Se había vencido a sí mismo definitivamente. Amaba al Gran Hermano (Orwell, 1949: 312).

Este párrafo nos permite observar el uso de un narrador heterodiegético e irónico como herramienta fundamental para construir el artefacto literario. Si la utopía perseguía una función crítica desde una posición de autoridad intelectual, la distopía busca la complicidad del lector mediante la ironía, para que reconozca los peligros y amenazas ya existentes en su sociedad, y que han sido «acelerados» (Jameson, 1994: 56) por la novela para estallar en un futuro próximo. La distopía procede por abstracción y magnificación: selecciona un aspecto potencialmente autodestructivo en la sociedad contemporánea - ya sea la lógica del consumo capitalista en Brave New World, el totalitarismo en Nineteen Eighty-Four o el patriarcado en The Handmaid's Tale- - y, como dice el mismo Orwell, sigue su desarrollo «to their logical consequences» (Claeys, 2010: 123).

Partiendo de Orwell, innumerables autoras y autores se han esforzado en aplicar esta operación sobre todo tipo de temas, desde las nuevas tecnologías de la información hasta el cambio climático, con el objetivo de mantener vivo el carácter admonitorio del género. Sin embargo, estas innovaciones en el plano temático no siempre se han visto acompañadas por una transformación de sus procedimientos compositivos, lo que ha contribuido a generar una imagen enquistada del género y, por lo tanto, una devaluación crítica del mismo. A lo que probablemente asistimos, sin embargo, es a un agotamiento de la fórmula fija de la distopía clásica, que para nada implica un anquilosamiento del impulso distópico y su capacidad de modulación. Desde la segunda mitad del siglo XX, los 


\section{Tropelías. Revista de Teoría de la Literatura y Literatura Comparada, 29 (2018)}

De la isla a la frontera. La problematización del espacio en la ficción distópica contemporánea

planteamientos de la posmodernidad han impulsado un cambio de paradigma cuyo impacto ha desplazado la función ostentada hasta entonces por la distopía clásica. Y es que, pese a su aparente pesimismo y crítica al progreso, esta no deja de alimentar una actitud positiva y confiada en la importancia de la cultura para impedir que una sociedad como la descrita se acabe instaurando. A este respecto, Fahrenheit 451 (Bradbury, 1953) es una obra paradigmática. La distopía clásica revela, pues, un cierto componente utópico, un deseo de ocupar la posición crítica que la utopía habría dejado de representar. Sin embargo, tras la muerte de las ideologías (Lyotard, 1979) y la concepción del mundo como «free play of masks and roles without content or substance» (Jameson, 1994: 18), la lógica posmoderna ya no contempla la confianza en ninguna transformación:

En el componente utópico de la Modernidad la imaginación se desembaraza de la autoridad y de un orden insatisfactorio para proyectarse en un «lugar de ninguna parte», a un futuro indeterminado que ha de constituir un nuevo estado de la humanidad, con la confianza en la propia capacidad de ampliar las condiciones de lucidez del hombre y la sociedad. [...] El componente utópico de la Posmodernidad, en cambio, se exaspera como distopía, un mal lugar, en las prácticas sociales y se expresa como denuncia catastrófica, como ultimidad de las formas y como desarticulación del cosmos (Dei, 2002: 80-81).

Valorar la importancia de este cambio de paradigma nos conduce a una lectura en clave distópica de una serie de textos que aportan elementos clave para una comprensión contemporánea de lo distópico, aunque no se reivindiquen abiertamente como tales ${ }^{4}$. En este sentido, podemos entender Ensaio sobre a cegueira (Saramago, 1995), donde una epidemia súbita e inexplicable deja ciega a toda la población, como un relato de transición entre ambos paradigmas: así como el arranque de la novela nos recuerda fuertemente a la distopía clásica, con los primeros infectados recluidos en un manicomio aislado y rodeado de militares, el desarrollo de la historia nos conduce a una progresiva implosión del modelo disciplinario, a medida que la ceguera alcanza a los guardianes, hasta una erosión completa de cualquier forma de autoridad. La salida de los ciegos del manicomio, una vez la cuarentena ha dejado de tener sentido, nos introduce en un escenario anómico de pérdida e involución, desconocido por la distopía clásica, y que encontramos en otras ficciones contemporáneas como High-Rise (Ballard, 1975) o The Walking Dead (Darabont, 2010), en las que la desintegración del mundo se traslada también a una constante oscilación del punto de vista entre distintos personajes, que sólo disponen de una percepción fragmentaria de la realidad que los rodea.

Frente a esta disolución del sentido, encontramos también ficciones que, partiendo del mismo sustrato distópico posmoderno, tematizan justo lo contrario: la emergencia de nuevas formas violentas de dominación en pro de una restauración del orden. En vez de devolvernos, sin embargo, a los planteamientos totalitarios de la distopía clásica, estas obras, entre las que se pueden contar The Handmaid's Tale o Soumission (Houellebecq, 2015), nos confrontan con el deseo secreto del sujeto posmoderno de ser sometido, de regresar al mito, a través de la adopción de una ley arbitraria —a menudo religiosa - capaz de sustraerlo de su vacío de autoridad. Una de las innovaciones más

\footnotetext{
${ }^{4} \mathrm{Al}$ contrario, lo que la mayoría de estos casos presentan es una hipertextualidad que va mucho más allá de la distopía clásica o que incluso se constituye, genealógicamente, de modo independiente. Como ya hemos indicado, lo que nos permite abordar este campo de estudio es un acercamiento genérico lectorial, haciendo uso de la «lógica analógica» descrita por Schaeffer (1989).
} 
interesantes que aquí encontramos es la introducción del relato de tránsito entre la sociedad contemporánea y la nueva sociedad distópica, indefectiblemente mucho más cercana en el tiempo que en ninguna distopía clásica. En The Handmaid's Tale, en la que no han pasado más de siete años desde el momento de cambio político, el pasado inmediato - coincidente con el presente del lector- es invocado de modo analéptico, remarcando la facilidad y el curso aparentemente irrefrenable con que se fueron sucediendo los acontecimientos hasta llegar a la forma social actual. En Soumission, donde nos encontramos con un escenario más propiamente ucrónico que futuro, plenamente coincidente con nuestro presente, el proceso de tránsito ocupa la totalidad del relato. Podemos observar también como, en ambos casos, el narrador heterodiegético desaparece frente a uno autodiegético, lo que refuerza el carácter subjetivo del texto y problematiza la perspectiva, al introducir un nuevo elemento de ironía ligado a una limitación del punto de vista del personaje, que, en The Handmaid's Tale, adopta los rasgos de un narrador poco fiable ${ }^{5}$. Así pues, el uso del condicional, en el último capítulo de Soumission, donde el personaje imagina (¿o recuerda?) los pasos que tendría que realizar para adherirse al nuevo régimen islámico, resulta extremadamente perturbador, puesto que no nos permite ubicar el punto temporal desde donde se construye el relato ni, por lo tanto, la suerte final del personaje tras su última afirmación: «No extrañaría nada [Et je n'aurais rien à regretter]» (Houellebecq, 2015: 281). La inconclusividad de este final proyecta un interrogante sobre el lector, al que se apela de nuevo de modo admonitorio, pero con una urgencia renovada: ya no se trata sólo de imaginar escenarios posibles partiendo de las tendencias actuales, sino de valorar si la realidad en la que nos hallamos está ya lista para su instauración.

En un plano configurativo, vemos, pues, cómo las ficciones distópicas contemporáneas pueden plantear innovaciones, modulaciones e incluso desligarse genealógicamente del legado de las distopías clásicas. La pregunta es, por lo tanto, cómo articular una lectura crítica que permita analizar y evaluar los cambios acaecidos en lo distópico, desde Huxley hasta The Walking Dead, y su vinculación con los discursos filosóficos, políticos y sociales contemporáneos, en un momento en que, como indica Jameson (2003: 76), «it is easier to imagine the end of the world than to imagine the end of capitalism». Para Jameson, el problema de nuestro presente recaería en la dificultad para ubicar una «diferencia radical», la posibilidad de un cambio capaz de volver a impulsar un proyecto utópico, ante un futuro que se presenta como pura repetición y monotonía. Asumiendo esta perspectiva, consideramos desde estas páginas que el eje articulador de todo discurso distópico se ubica precisamente en la relación dialéctica que dicho discurso traba con el pensamiento utópico de su momento. La problematización de esta dialéctica puede constituir, por lo tanto, un buen criterio de análisis para aproximarse al fenómeno distópico en su conjunto. Y acaso donde esta problematización se deja observar con mayor

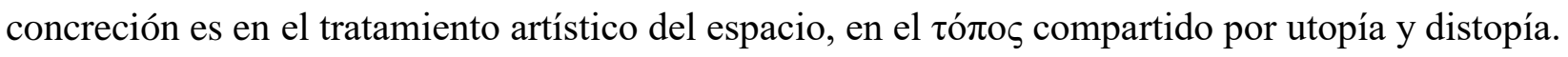

Para ello, puede resultar útil recurrir al concepto bajtiniano del cronotopo. Según Bajtín (1975: 238), «la imagen del hombre en la literatura es siempre esencialmente cronotópica». Para Bajtín, el

\footnotetext{
${ }^{5}$ Este elemento fue eliminado en la realización de la ficción audiovisual seriada The Handmaid's Tale (2017), donde el personaje de Offred es presentado como una heroína.
} 


\section{Tropelías. Revista de Teoría de la Literatura y Literatura Comparada, 29 (2018)}

De la isla a la frontera. La problematización del espacio en la ficción distópica contemporánea

cronotopo es el elemento clave a cuyo alrededor se construye todo género literario, y que permite entender los códigos que rigen un determinado mundo de ficción; el cronotopo implica una relación de absoluta interdependencia entre tiempo y espacio, de modo que sólo en la conjunción de estas dos coordenadas es posible situarse realmente en su interior. Por supuesto, ni «espacio» ni «tiempo»son, para Bajtín, equivalentes a «ubicación» o a «época». Lejos de ser meros contenedores para la acción, cada uno de estos conceptos expresa unas cualidades que determinan las posibilidades que un mundo dado pone al alcance de sus personajes y, a través suyo, la imagen de la existencia que dicho mundo nos devuelve.

Desde este punto de vista, podríamos decir que el tiempo, en la distopía clásica, acostumbra a expresarse como un tiempo artificial y automatizado; el reloj que «da las trece» en Nineteen EightyFour o las estrictas rutinas de las criadas en The Handmaid's Tale son un buen ejemplo de ello. Los personajes están inmersos en un bucle, y son receptores de violencias infligidas desde el exterior, de modo que el control social constante configura la estrecha retícula en cuyo interior pueden moverse. El espacio de la distopía clásica se configura, por otro lado, como un laberinto. Se trata de un espacio altamente ritualizado, con una oposición muy clara entre «lugares»y «espacios de tránsito». Mientras que los lugares cerrados definen posiciones sociales en las que el sujeto puede sentirse seguro, los espacios abiertos destinados al tránsito representan el peligro y propician el extravío.

Así como para Bajtín el espacio es inseparabale del tiempo, para Lotman (1970) este no puede entenderse si no es a través del conflicto. El espacio siempre se halla, desde este punto de vista, en tensión con «otro» espacio, aunque este no sea directamente representado. De nuevo, no nos referimos aquí a una oposición física, sino a una diferencia que adquiere sentido en función del valor simbólico, la percepción psicológica o los códigos de verosimilitud que se concedan a cada uno de estos espacios. Aunque puede rastrease en tantos niveles como se quiera, la mínima expresión del modelo espacial se encuentra en la oposición binaria. En palabras de Lotman (1970: 281):

[...] el rasgo topológico fundamental del espacio es el límite. El límite divide todo el espacio del texto en dos subespacios que no se intersecan recíprocamente. Su propiedad fundamental es la impenetrabilidad. La forma en que el límite divide el texto constituye una de sus características esenciales. Puede ser en propios y ajenos, vivos y muertos, ricos y pobres. Lo importante es otra cosa: el límite que divide el espacio en dos partes debe ser impenetrable, y la estructura interna de cada uno de los subespacios, distinta.

El detonante de la acción, en cualquier texto literario, tiene lugar a través del «franqueo del límite topológico fundamental en su estructura espacial» (Lotman, 1970: 291), lo que nos remite nuevamente al cronotopo: lo que activa la acción de Madame Bovary es, finalmente, el intento de Emma de huir del cronotopo inmóvil de la ciudad de provincias a través del cronotopo aventurero de la novela sentimental, mientras que la fricción que se establece entre estos dos conflictos da lugar al espacio irónico, de desencaje, que produce la novela de Flaubert. Así pues, la transgresión del modelo espacial no sólo actúa como un factor dinámico para producir un argumento, sino que nos sirve para observar los problemas éticos y estéticos que atraviesan una determinada obra. Como remarca Bajtín, cada movimiento o género literario privilegia el uso de un determinado cronotopo, de acuerdo con la visión del mundo de la que, históricamente, dicho movimiento o género disponga. La visión del mundo que 
nos ofrece el cronotopo debe, sin embargo, ser completada dialécticamente con lo que el cronotopo no es; es decir, con la tensión existente con otros espacios que tratan de invadirlo. Desde este punto de vista, la problematización de los cronotopos o la transgresión de códigos procedentes de distintos géneros puede reflejar momentos históricos de crisis o de cambio de paradigma, que a menudo repercuten tanto en la literatura como en otros ámbitos discursivos, quizá menos evidentes pero extremadamente significativos, como la percepción de los espacios y el valor social que se confiere a su organización (Sennett, 1994).

La isla representa el espacio de la literatura utópica por excelencia. Desde la obra inaugural de More, el espacio oculto, aislado y prácticamente inalcanzable se ha convertido en el mejor lugar posible para esconder el «no lugar». Las sociedades utópicas pueden situarse tanto en islas —en el sentido más literal de la palabra - como en regiones que dispongan de rasgos de insularidad: este sería el caso de la sierra montañosa que rodea El Dorado en el Candide de Voltaire, pero también de las utopías que se ubican en el futuro o en un tiempo alternativo o ucrónico (Vieira, 2010: 9-15)—, así como en el mundo de los sueños. El motivo de la isla configura un modelo espacial paradigmático: rodeada por un límite casi totalmente infranqueable, la isla se escinde radicalmente de lo que la rodea, y le da la espalda. Al mismo tiempo, la isla reconoce este límite como un cuerpo extraño, puesto que no hay ninguna otra división en su interior. Por supuesto, hay divisiones sociales orientadas a la optimización de las funciones de la sociedad, pero no hay disidencia ni conflicto. La utopía representa, por lo tanto, el ideal de la máxima gobernabilidad, la identidad absoluta entre lugar y proyecto, como si el espacio que la sociedad utópica ocupa no pudiera contener nada excepto la perfección de dicha sociedad.

Es interesante ver cómo el modelo de la isla se mantiene en algunos de los primeros textos literarios donde encontramos visiones distópicas. Este es, notablemente, el caso de The Island of Doctor Moreau. Tras sufrir un naufragio, el protagonista Edward Prendick es rescatado por un barco que lo traslada hasta una isla remota y, según nos indica el prólogo, desconocida, donde será acogido por el doctor Moreau, un biólogo repudiado por la comunidad científica a causa de sus heterodoxas prácticas de vivisección, y que se exilió para continuar con sus experimentos, con el objetivo de transformar animales en una versión maltrecha de seres humanos. A diferencia de lo que encontramos en la isla utópica, la isla del doctor Moreau está rígidamente dividida por límites interiores, que distribuyen los espacios según una gradación que va de civilización a bestialidad: el edificio donde residen los humanos - Prendick, el doctor Moreau y su socio_-, el poblado primitivo de los hombres bestia y el bosque. Esta gradación también implica una jerarquía de poder: así como el control humano sobre los animales es más fuerte en la casa de Moreau, este se diluye a medida que se adentra en el bosque y en la parte irracional de las criaturas. The Island of Doctor Moreau no participa tanto del género utópico como de la narrativa de terror, pero el legado de la utopía se invoca en él precisamente a través de la elección de la isla como espacio. El sueño divino de Moreau constituye, si se quiere, una utopía privada, pero que simbólicamente alcanza a la ciencia en su conjunto. Lo que esta isla representa es una sustitución del ideal científico del progreso por un mal uso de la ciencia, en una oposición 


\section{Tropelías. Revista de Teoría de la Literatura y Literatura Comparada, 29 (2018)}

De la isla a la frontera. La problematización del espacio en la ficción distópica contemporánea

reforzada por la introducción de una de las delimitaciones espaciales más fuertes de la isla en el interior mismo de la casa, la que separa el cuarto de Prendick del laboratorio de Moreau. El laboratorio, espacio que debería constituir el polo de la humanidad, aparece como un espacio de tortura y sufrimiento, convirtiéndose, por lo tanto, en un núcleo de bestialidad en el corazón de la ciencia.

Ahora bien, no es hasta llegar a la grieta donde viven los hombres bestia, descrita como un «extraño callejón» (Wells, 1896: 63), superpoblado y hediondo, que nos acercamos propiamente al escenario urbano característico de la ficción distópica. La distopía clásica abandona el modelo insular propuesto por Wells y presupone, en cambio, un mundo único, que ha diluido sus fronteras tanto espaciales (por ejemplo, con los grandes bloques mundiales de Nineteen Eighty-Four) como temporales (con la reescritura o supresión directa del pasado). En Brave New World, la excesiva especialización mantiene a todo el mundo en la ignorancia, mientras que en Fahrenheit 451 se castra sistemáticamente la imaginación, lo que imposibilita la evasión a otro mundo. En cierto modo, esta figuración de un mundo único sin alternativa no es sino una reformulación de la insularidad utópica, con la diferencia de que, en lugar de ser vistos como santuarios o reductos de pureza a los que es extremadamente difícil acceder, los espacios distópicos se nos presentan como prisiones, de las que es imposible huir. En este sentido, la distopía clásica plantea un modelo espacial más perverso que el de la isla, heredero de las transformaciones urbanas y demográficas de los siglos XIX y XX, a través de lo que Italo Calvino dio en llamar «ciudades contínuas»: una extensión prácticamente infinita e indiferenciada de tejido urbano, donde es difícil orientarse y de la que, ante la ausencia de límites claros, el sujeto no puede apropiarse.

Así como el modelo utópico define su identidad mediante la isolación y se construye, por así decirlo, al abrigo de la frontera, la distopía se ve constituida como tal por la ausencia de fronteras exteriores. La fuga de Montag, el protagonista de Fahrenheit 451, es el único caso, entre todos los considerados, en que un personaje cruza el umbral de la sociedad distópica e ingresa en un mundo alternativo. En todos los demás, el intento de fuga no sólo termina en fracaso (pensemos en el intento de John de convertirse en eremita en Brave New World o en la tentativa de Winston de unirse a un movimiento de resistencia en Nineteen Eighty-Four, pero también en la progresiva incapacidad de abandonar el rascacielos que desarrollan los personajes de High-Rise), sino que ni siquiera permite entrever la existencia de un umbral. En The Handmaid's Tale, Margaret Atwood nos ofrece uno de los retratos más sintéticos de este cronotopo: «Estamos en el centro de Gilead, donde la guerra no llega salvo a través de la televisión. No estamos seguras de dónde están los límites, varían según los ataques y contraataques. Pero éste es el centro, y aquí nada se mueve. La República de Gilead, decía Tía Lydia, no tiene fronteras. Gilead está dentro de ti» (Atwood, 1985: 25-26). Y, más adelante: «De vez en cuando variamos el itinerario; no hay nada que lo prohíba, siempre que permanezcamos dentro del límite de las barreras. Una rata que está dentro de un laberinto es libre de ir a cualquier sitio, siempre que permanezca dentro del laberinto» (Atwood, 1985: 152).

No sólo encontramos el cronotopo del laberinto en la distopía clásica, donde este se liga a la figura del estado impenetrable propio de la Guerra Fría, sino también en las distopías basadas en el 
colapso social: The Walking Dead y Ensaio sobre a cegueira plantean un mundo igualmente laberíntico, del que también es imposible huir.

Ahora bien, la ausencia de fronteras exteriores no desplaza la frontera fuera del género distópico; más bien sucede todo lo contrario. La lógica predominante en la ficción distópica es la de la frontera, entendida como espacio de excepción y de privación de derechos. Desde este punto de vista, podemos considerar que la distopía clásica se dedicó a tematizar y a ampliar la frontera implícita en el modelo espacial de la isla, sin referirse explícitamente a ella. En otras palabras, estas distopías nos plantean la pregunta de cuál es el precio de represión e incluso exterminio a pagar para que una determinada sociedad pueda alcanzar su ideal de progreso y buen funcionamiento. Este estado de excepción permanente ${ }^{6}$ es explícitamente legitimado en distopías como Nineteen Eighty-Four o The Handmaid's Tale, a través de la referencia a la guerra exterior, mientras que en otros casos, como en The Walking Dead, aparece como resultado de la caída de las estructuras encargadas de mantener el orden social.

Desde un punto de vista crítico, podemos ver The Walking Dead como una serie en la que un grupo de personajes privilegiados, que no pertenecen al espacio de la frontera, se ven obligados a sobrevivir en ella, junto con sus habitantes genuinos (zombis y saqueadores), a los que se imagina como un «Otro» radical. Así pues, la serie plantea una fuerte división entre «nosotros» y «ellos», entre vivos y no muertos (undead), del mismo modo que en The Handmaid's Tale se utiliza el término de «no mujeres» (unwomen) para referirse a las disidentes, en una oposición excluyente especialmente presente en el discurso distópico. The Walking Dead es una serie sobre la seguridad, no azarosamente exitosa en un tiempo dominado por el miedo al terrorismo y la desconfianza para con la protección que el individuo puede esperar del Estado. Desde este punto de vista, podemos entender que, desde el interior de la lógica distópica que regula su universo, la serie plantee un retorno al modelo insular de la utopía. Tras haber recorrido grandes distancias en el mundo hostil que los rodea, los personajes de The Walking Dead descubren que el mejor modo de sobrevivir consiste en abandonar el nomadismo, establecerse en un lugar con suficiente espacio para vivir cómodamente y cultivar, y construir muros a su alrededor: este es el modelo que el grupo de Rick Grimes adopta al llegar a Alexandria en la quinta temporada de la serie, pero también el de otros grupos como Hilltop o The Kingdom ${ }^{7}$. La idea fundamental que se reinventa en estas pequeñas islas es la de la comunidad: ante la privación constante de derechos que supone el estado de excepción, la comunidad puede realizar de nuevo algo parecido al ideal de gobernabilidad planteado por las utopías, uniendo fuerzas contra un enemigo «otro» que se encuentra al otro lado del muro.

El modelo de la isla aparece también en Soumission, donde Michel Houellebecq nos sitúa ante el escenario hipotético de una última vuelta de las elecciones francesas disputada entre el Frente Nacional de Marine Le Pen y un partido islámico. En Soumission, el Hexágono francés se convierte

\footnotetext{
${ }^{6}$ En lo referente a la dialéctica entre estado de excepción y soberanía, vid. Agamben (2003).

${ }^{7}$ Vale la pena observar cómo, en una operación hipertextual, The Walking Dead incorpora ciertos elementos simbólicos (el sombrero y la estrella de sheriff de Rick Grimes, las herrerías de Hilltop o los elementos medievalizantes presentes en The Kingdom) que remiten a géneros con una carga tanto utópica como fundacional en la tradición norteamericana, como el western o las novelas de caballerías.
} 


\section{Tropelías. Revista de Teoría de la Literatura y Literatura Comparada, 29 (2018)}

De la isla a la frontera. La problematización del espacio en la ficción distópica contemporánea

en la encarnación de la isla utópica, entendida como receptáculo simbólico de la tradición y los valores atribuidos a Occidente. Es precisamente la amenaza que representa el ascenso al poder de la Hermandad Musulmana (que defiende, entre otras cosas, la poligamia masculina y la sumisión patriarcal de las mujeres) sobre estos valores lo que introduce el conflicto y la posibilidad de transgresión del espacio utópico, desde una oposición entre lo propio y lo ajeno. La habilidad de Houellebecq consiste en problematizar la definición de estos conceptos, a través de la dificultad para identificarse, desde un pensamiento de izquierdas, con la posición de Le Pen y del así llamado «movimiento identitario», dando lugar a un estado de estupor y extrañamiento ante la realidad: «Esa noche era el turno de la candidata del Frente Nacional, que declaraba su amor por Francia ("¿pero qué Francia?", le replicaban sin gran pertinencia comentaristas de centro izquierda), y me pregunté si mi vida amorosa se había acabado verdaderamente» (Houellebecq, 2015: 34-35).

El texto de Houellebecq retoma el género distópico para hablar de la sensación de decadencia y pérdida de sentido en Occidente, y diagnostica un deseo oculto de sumisión en el sujeto occidental, lo que explica la «lánguida y tácita aceptación» (Houellebecq, 2015: 193) con la que el proceso de imposición de la Hermandad Musulmana tiene lugar. Dicho proceso comporta, por así decirlo, una especie de implosión de la isla utópica, la cual cede voluntariamente su especificidad para pasar a ser administrada desde el exterior.

High-Rise nos ofrece otra revisión distópica del modelo insular. En este caso, J. G. Ballard se remonta al mito de Robinson Crusoe, remplazando la isla desierta en las antípodas de la civilización por un lujoso rascacielos de nueva construcción. High-Rise muestra cómo las desigualdades existentes entre sus habitantes - todos ellos exitosos profesionales liberales - se convierten progresivamente en conflictos territoriales que los enfrentan en función de la altura a la que se sitúa su apartamento, hasta el punto de conducir a una verdadera guerra de clanes. En la última fase de este conflicto, los habitantes del rascacielos devienen prácticamente animales, que atacan y asesinan a cualquier persona que se encuentren en su búsqueda de comida o refugio. La civilización perdida ya no configura el espacio de seguridad, recuperable al someter nuevamente a la naturaleza, que representaba para Robinson; al contrario, High-Rise apunta al componente alienante de la civilización como acicate de su propio colapse. A diferencia de Robinson, los personajes ya no pueden buscar sentido en la civilización, transformada en un montón de ruinas vacías:

Aún sin saber cuánto tiempo llevaba despierto, o qué había hecho media hora antes, Laing se sentó entre las botellas vacías y los desechos del suelo de la cocina, las ruinas del refrigerador y la máquina de lavar, que ahora utilizaban como depósitos de residuos. Le costaba recordar para qué habían servido antes. Hasta cierto punto ahora tenían un nuevo significado, un papel que él aún no entendía. Hasta el aspecto decadente del rascacielos era un modelo del mundo que los esperaba en el futuro, un paisaje más allá de la tecnología donde todo estaba en ruinas, o, más ambiguamente, recompuesto de algún modo imprevisto pero más significativo. Laing lo pensó un momento. A veces le costaba no creer que estaban habitando en un futuro que había llegado ya, un futuro agotado (Ballard, 1975: 207-208).

En High-Rise, Ballard refleja dos horizontes distópicos de la posmodernidad: por un lado, el miedo ante el hecho de que la sociedad no sea sino un simulacro (Baudrillard, 1990), y que perviva sólo como tal, en la virtualidad de los objetos abandonados y sin uso, y, en segundo lugar, la posibilidad 
de reencontrar el sentido perdido en un «nuevo orden social» (Ballard, 1975: 190), aunque esté gobernado por la ley de la jungla o por la organización de grupos asesinos. Este se constituye como el nuevo horizonte al que parecen aproximarse los supervivientes de High-Rise, como Laing, que se siente «más feliz que nunca» (Ballard, 1975: 217) y que, viendo como los primeros habitantes llegan al rascacielos vecino, los observa «satisfecho, listo para darles la bienvenida a este nuevo mundo» (Ballard, 1975: 245). Mientras la dimensión vertical del edificio continúa representando la posibilidad de un ascenso, su interior es progresivamente invadido por una superposición absoluta de islas y de fronteras, mediante la proliferación de barricadas que dificultan cada vez más el movimiento. Ballard nos plantea, pues, lo contrario que encontramos en The Walking Dead; así como allí los muros representaban la posibilidad de fundar una nueva comunidad y disponer de una identidad opuesta al mundo exterior, en High-Rise estos contribuyen a la atomización social y a la pérdida de los valores individuales y colectivos, ante de la asunción de la fuerza como único criterio válido. Las islas que delimitan estas barricadas se convierten en madrigueras, sorprendentemente similares a las que encontrábamos en la ciudad de los hombres bestia en The Island of Doctor Moreau, y cada vez más inútiles como refugio, a medida que defenderlas se vuelve más costoso e invadirlas, más fácil.

En The Island of Doctor Moreau, la frontera entre el buen y el mal uso de la ciencia constituía un límite claro y que, consiguientemente, podría aislar la negatividad del cuerpo científico confinándola a una isla. En la distopía clásica, la idea de la isla es devorada por la de una frontera sin fin, en una distribución del espacio que no permite ni la evasión ni la instauración de un orden alternativo. La distopía contemporánea, en cambio, parece obsesionada por la dialéctica entre isla y frontera, y así lo refleja en una sorprendente variedad de conflictos espaciales, cuya territorialidad alcanza desde la concreción espacial de The Walking Dead, donde las vallas constituyen la defensa paradigmática contra el Otro, hasta el propio cuerpo como espacio en disputa, como plantea The Handmaid's Tale, donde el cuerpo femenino, convertido en un aparato de propiedad estatal con la única función de reproducirse, se ha convertido en cronotopo:

Soy una nube solidificada alrededor de un objeto central, en forma de pera, que es patente y más real que yo y brilla en toda su rojez dentro de su envoltura translúcida. En el interior hay un espacio inmenso, oscuro y curvo como el cielo nocturno, pero rojo en lugar de negro. [...] Todos los meses aparece una luna gigantesca, redonda y profunda como un presagio. Culmina, se detiene, continúa y se oculta de la vista, y siento que la desesperación se apodera de mí como un hambre voraz. Sentir ese vacío una y otra vez. Oigo mi corazón, ola tras ola, salada y roja, incesantemente, marcando el tiempo (Atwood, 1985: 70).

Este interés por pensar y repensar las interacciones entre isla y frontera nos permite observar, como rasgo distintivo de las ficciones distópicas producidas en los últimos años, un fuerte retorno a la idea utópica de la fundación de una comunidad. Ya no se tematiza la salida individual de la alienación que guiaba los esfuerzos de los personajes de las distopías clásicas, sino que se presentan problemas que sólo pueden afrontarse de modo colectivo. No extraigamos, sin embargo, ninguna conclusión moral de ello. La distopía contemporánea se enfrenta a la comunidad como fenómeno problemático, ya sea para hablar de la crisis de la democracia y la cultura occidental como sucede en Soumission, o bien para reforzar las imágenes de miedo ante el Otro como sucede en The Walking Dead, donde la 
supervivencia de la comunidad hace necesario el uso de la violencia contra quienes no forman parte de ella. Desde este punto de vista, José Ovejero (2017) no duda en sentenciar que «la utopía inconfesada del siglo XXI [...] es la seguridad», cuya lógica también predomina en el actual diseño de barrios residenciales en forma de «privatopías», desde una «security-obsessed fortress mentality» (MacLeod y Ward, 2002: 160).

Esto nos permite enlazar con un segundo aspecto clave: así como la utopía nació como un discurso literario y político con vocación de incidir sobre lo real, la ficción distópica también ha acabado por moldear un discurso provisto de esta incidencia directa. El estudio de los mecanismos formales y los problemas planteados por la ficción distópica puede, por lo tanto, aplicarse al análisis crítico de nuestro presente, donde los espacios de excepción y de privación de derechos disponen de una existencia nada especulativa. Las islas y las fronteras conviven en nuestro presente (no desde un punto de vista binario, sino, como apunta Nöth (2015: 20), como «multiplicity of boundaries creating intersecting spaces»), y donde sólo el privilegio de encontrarnos en un lado u otro del muro determina nuestra posición en un régimen utópico o distópico. La oposición entre «dentro» y «fuera» que hallamos explícitamente expresada en The Walking Dead es la misma que estructura el discurso político de Donald Trump (utópico en su ideal de restaurar la grandeza nacional, distópico en su diagnóstico de la realidad).

Como dice Rancière (2000: 62), «la politique et l'art, comme les savoirs, construisent des "fictions", c'est-à-dire des réagencements matériels des signes et des images, des rapports entre ce qu'on voit et ce qu'on dit, entre ce qu'on fait et ce qu'on peut faire». Pero allí donde el arte detecta tensiones y plantea problemas, el discurso distópico, aplicado a la política, dispone de un peligroso poder performativo. Los procesos de gentrificación nos permiten, por ejemplo, ver como «the various attempts to contrive urban utopias are generating a flip side: the spaces that remain untouched by such endeavours are gradually assuming dystopian characteristics» (MacLeod y Ward, 2002: 161).

Desde este punto de vista, aparece la posibilidad de desarrollar una metodología de análisis del discurso distópico que, respaldándose en los modelos planteados por el arte y la literatura, permita tratar las ficciones políticas como tales, e investigar sus correspondencias con lo real.

\section{Referencias bibliográficas}

AgAmben, Giorgio (2003): Stato di eccezione. Homo sacer, II, 1. Turín, Bollati Boringhieri.

Atwood, Margaret (1985): El cuento de la criada. Trad. de Elsa Mateo. Barcelona, Seix Barral, $2^{\mathrm{a}}$ ed., 1987.

Bajtín, Mijaíl M. (1975): Teoría y estética de la novela. Trabajos de investigación. Trad. Helena S. Kriúkova y Vicente Cazcarra. Madrid, Taurus, 1989.

BALlard, J.G. (1975): Rascacielos. Trad. Manuel Figueroa. Barcelona, Minotauro, 2003.

BAUDRILLARD, Jean (1990): La transparencia del mal. Ensayo sobre los fenómenos extremos. Trad. Joaquín Jordá. Barcelona, Anagrama, 1991. 
Bradbury, Ray (1953): Fahrenheit 451. Trad. Alfredo Crespo. Barcelona, Plaza \& Janés, 1967.

BudAKOV, Vesselin M. (2010): «Dystopia: An Earlier Eighteenth-Century Use», Notes and Queries, $57 / 1$, pp.86-88.

- (2011): «Cacotopia: An Eighteenth-Century Appearance in News from the Dead (1715)». Notes and Queries, 58/3, pp.50-53.

ClaEYs, Gregory (2010): «The Origins of Dystopia: Wells, Huxley and Orwell», en G. ClaEYs, ed., The Cambridge Companion to Utopian Literature. Newcastle upon Tyne, Cambridge University Press, pp. 107-132.

- (2011): Utopía. Historia de una idea. Trad. María Condor. Madrid, Siruela.

- (2013): «Three Variants on the Concept of Dystopia», en F. VIEIRA, ed., Dystopia(n) Matters: On the Page, on the Screen, on the Stage. Newcastle upon Tyne, Cambridge Scholars Publishing, pp. 14-18.

DARABOnT, Frank (2010): The Walking Dead. Estados Unidos, AMC.

DEI, H. Daniel (2002): Lógica de la distopía. Fascinación, desencanto y libertad. Buenos Aires, Docencia.

Di Minico, Elisabetta (2015): Antiutopía y control. La distopía en el mundo contemporáneo y actual. Barcelona, Universitat de Barcelona; en http://hdl.handle.net/10803/351716 (última consulta, 86-2017).

Domingo, Andreu (2008): Descenso literario a los infiernos demográficos. Distopía y población. Barcelona, Anagrama.

HorkHEIMER, Max - AdORnO, Theodor W. (1969): Dialéctica de la Ilustración. Fragmentos filosóficos. Trad. J. J. Sánchez. Madrid, Trotta, $3^{\text {a }}$ ed., 1998.

HouelleBeCQ, Michel (2015): Sumisión. Trad. Joan Riambau. Barcelona, Anagrama.

HuXley, Aldous (1932): Un mundo feliz. Trad. Ramon Hernández García. Barcelona, Debolsillo, 2013.

KUMAR, Krishan (2013): «Utopia's Shadow», en F. VIEIRA, ed., Dystopia(n) Matters: On the Page, on the Screen, on the Stage. Newcastle upon Tyne, Cambridge Scholars Publishing, pp. 19-22.

JAMESON, Fredric (1994): The Seeds Of Time. New York, Columbia University Press. (2003): «Future City», New Left Review, 21, pp. 65-79.

LÓPEZ KELlER, Estrella (1991): «Distopía: otro final de la utopía». Revista Española de Investigaciones Sociológicas, 55, pp. 7-23.

LOTMAN, Yuri M. (1970): Estructura del texto artístico. Trad. Victoriano Imbert. Madrid, Istmo, 1988.

LUKÁCS, György (1920): Teoría de la novela: un ensayo histórico-filosófico sobre las formas de la gran literatura épica. Trad. Micaela Ortelli. Buenos Aires, Ediciones Godot Argentina, 2010.

LYOTARD, Jean-François (1979): La condición postmoderna. Informe sobre el saber. Trad. Mariano Antolín Rato. Madrid, Cátedra, 1987.

MACLEOD, Gordon - WARD, Kevin (2002): «Spaces of Utopia and Dystopia: Landscaping the Contemporary City», Geografiska Annaler. Series B: Human Geography, 84/3-4, pp. 153-170. 
Moreno, Fernando Ángel (2013): Teoría de la literatura de ciencia ficción. Poética y retórica de lo prospectivo. Madrid, Portal Editions.

NöтH, Winfried (2015): «The Topography of Yuri Lotman's Semiosphere». International Journal of Cultural Studies, 18/1, pp. 11-26.

ORWELL, George (1949): 1984. Trad. Rafael Vázquez Zamora. Barcelona, Destino, 1980.

OVEJERO, José (2017): «No os preocupéis, no sois libres», La Marea, en http://www.lamarea.com/ 2017/05/23/no-os-preocupeis-no-sois-libres/ (última consulta: 10-06-2017).

PAVEL, Thomas (2003): Representar la existencia. El pensamiento de la novela. Trad. David Roas. Barcelona, Crítica, 2005.

RANCIÈRE, Jacques (2000): Le partage du sensible. Esthétique et politique. París, La Fabrique. (2007): Politique de la littérature. París, Galilée.

RICOEUR, Paul (1965): Freud: una interpretación de la cultura. Trad. Armando Suárez. México, Siglo XXI, 1970.

SARAMago, José (1995): Ensayo sobre la ceguera. Trad. Basilio Losada. Madrid, Alfaguara, 2011.

SCHAEFFER, Jean-Marie (1989): Qu'est-ce que c'est un genre littéraire? París, Seuil.

SENNETT, Richard (1994): Carne y piedra. El cuerpo y la ciudad en la civilización occidental. Trad. César Vidal. Madrid, Alianza, 1997.

Trousson, Raymond (1979): Historia de la literatura utópica. Viajes a países inexistentes. Trad. Carlos Manzano. Barcelona, Edicions 62, 1995.

VIEIRA, Fátima (2010): «The Concept of Utopia», en G. ClAEYs, ed., The Cambridge Companion to Utopian Literature. Newcastle upon Tyne, Cambridge University Press, pp. 3-27.

Wells, H. G. (1896): La isla del dr. Moreau. Trad. Catalina Martínez Muñoz. Madrid, Alianza, 2014. 